\title{
Article \\ Science Cafés, Science Shops and the Lockdown Experience in Florence and Rome ${ }^{\dagger}$
}

\author{
Giovanna Pacini ${ }^{1,2}, * \mathbb{C}$, Cinzia Belmonte ${ }^{3}$ and Franco Bagnoli ${ }^{1,2,4, *(1)}$ \\ 1 Department of Physics and Astronomy and Center for the Study of Complex Dynamics, \\ University of Florence, Via G. Sansone 1, 50019 Sesto Fiorentino (FI), Italy \\ 2 Associazione Caffè-Scienza Firenze-Prato, via Madonna del Piano 10, 50019 Sesto Fiorentino (FI), Italy \\ 3 FormaScienza, via S. Pincherle, 173-00146 Roma, Italy; cinzia.belmonte@formascienza.org \\ 4 Istituto Nazionale di Fisica Nucleare, sez. Firenze, Via G. Sansone 1, 50019 Sesto Fiorentino (FI), Italy \\ * Correspondence: giovanna.pacini@unifi.it (G.P.); franco.bagnoli@unifi.it (F.B.); Tel.: +390554572330 (G.P.) \\ + This paper is an extended paper presented at the International Conference on Internet Science in Perpignan, \\ France, in 2-5 December 2019.
}

Received: 12 June 2020; Accepted: 1 July 2020; Published: 8 July 2020

\begin{abstract}
The lockdown was crucial to stop the COVID-19 pandemic in Italy, but it affected many aspects of social life, among which traditional live science cafés. Moreover, citizens and experts asked for a direct contact, not relying on mass-media communication. In this paper, we describe how the Florence and Rome science cafés, contacted by citizens and experts, either directly or through the Florence science shop, responded to these needs by organizing online versions of traditional face-to-face events, experiencing high levels of participation. The science café methodology was also requested by a high school that needed to conclude an engagement experience with students and their families. We also report the results of a survey about the satisfaction of this new methodology with respect to the old one.
\end{abstract}

Keywords: SARS-CoV-2; COVID-19; lockdown; science cafés; science shop; public engagement

\section{Introduction}

The lockdown after the SARS-CoV-2 pandemic has affected many aspects of life, especially for what concerns all activities that imply contact and sharing of information. In particular, Italy was one of the first nations to experience the complete blockage of in-person encounters, for as long as two months (from 9th March to 3rd May).

The effectivity of restriction measures depends on their degree of acceptance by citizens, which in turn depends on the information available, both coming from "official" channels and gathered through social media or other individual ways. In Italy, almost all journal and broadcast media insisted on enforcing the restriction measures, but several "underground" criticisms spread out in social media such as WhatsApp, increasing in time with the decrease of the "risk perception" and the will/need of restoring some aspects of "normal" social life.

Indeed, there is a strong, albeit poorly documented in quantitative terms, interplay between the spreading characteristics of a disease and the individual behavior; for instance, despite the huge return to their families in South Italy of people escaping from the forecasted quarantine in North Italy (around the 21st of February 2020), very few cases finally manifested, possibly due to a self-imposed quarantine, or at least to a careful obedience to imposed restrictions. The effects of the risk perception on the mitigation of an epidemics is introduced (in modeling) in Ref. [1], studied in Refs. [2,3] (see also Ref. [4]), and, for what concerns the COVID-19 pandemics, in Ref. [5]. 
The authorities were quite concerned by the possibility of a massive non-observance of the restrictions but could only exploit massive campaigns on mass-media. In addition, many entertainment companies and social organizations tried to contribute, for instance setting up online events and shows. The organization of rational discussions and reflection was much more difficult.

In general, the main difficulty encountered is that of involving citizens. This is particularly true for activities and projects concerning sustainability and social promotion themes, for which involved citizens are supposed to modify their habits. For instance, many projects about Collective Awareness Platforms for Sustainability and Social Innovation (CAPS) started with quite innovative ideas but failed due to the lack of participation [6-10].

In Florence and Rome, two associations of volunteers (Caffè-Scienza Firenze and FormaScienza Roma) are devoted to organizing public debates, in the spirit of science cafés, as illustrated in Section 2. In particular, the Florence association is in strict contact with the Interdepartmental Center for the Study of Complex Dynamics (CSDC) [11] of the University of Florence [12]. The science café modality has been adopted as an engagement tool by the University of Florence science shop [13], which was born tanks to European Projects (InSPIRES) [14], in the spirit of the Responsible Research and Innovation (RRI) principles [15].

During the lockdown, these association stopped their activity, and many programmed events were canceled. However, their reference community asked for both the possibility of discussing aspects related to the COVID-19 pandemics directly with experts and to continue the practice of science cafés in some online way. In the case of Rome, the main requests arrived from experts, who were dissatisfied by the lack of specific and detailed information about the virus. In Florence, the public of the local science shop exhorted the Caffè-Scienza association to continue organizing such events. In both cases, the response was to switch to completely online events, exploiting the previous knowledge about streaming live science cafés.

After the first events, some teachers of a high school asked for help in completing a series of conferences about blood donation, interrupted by the lockdown.

In the following, we report about this experience (which has also been partially replicated in Alessandria). In Section 2, we recall the history and spirit of science café, and, in Section 3, what a science shop is. Finally, in Section 4, we describe the communication situation during the pandemic, the counteractions organized, and the reactions of the public. Conclusions are drawn in the last Section.

\section{Science Cafés}

In science communication, many of the methods provide for a passive presence of the public, with a "one way" mechanism in which the emitter is the expert and the recipient is the people: the information flow from experts to participants.

A conference, for instance, is normally organized in a lecture hall of a university or an institutional place, with the expert being in the "chair" and the public in the parterre. In a sense, it is as if the conference took place in the expert's house and the participants were guests.

As a result, the flow of information and interactions are almost always one-way, with a few questions from the audience, confined at the end of the intervention. Participation is therefore very selective and is unlikely to involve a generic public. From the point of view of the interaction, the conference is still better than other forms of dissemination such as articles, television, and radio broadcasts, but it reaches a smaller audience.

In 1992, Duncan Dallas, a former BBC Director, launched in Leeds the idea of a science café, anticipating the revolution in science communication from the "Public Understanding of Science" to the "Public Engagement of Science and Technology" [16]. A science café is a conference turned upside down [17-19]. The advent of the Internet has also allowed using tools such as podcasts to distribute the recording of events and even streaming, introduced mainly from the science café in Florence, to be able to reach people who for geographical or health reasons cannot reach the venue of the event but want to participate at distance [20]. 
One of the most important aspects of this methodology is related to its cognitive implications. From one side, there is the need to actively involve the public in the transmission of information, avoiding the passive TV effect. Simultaneously, one wants to avoid participants taking a premature position on hot topics, since in this case there is the risk of polarizing the audience that is no longer effectively communicating. The science café method is based on avoiding the participation of counter-posed experts, and to let public pose questions at any time, but possibly avoiding expressing their opinion until the end. Many of these aspects survive also when using virtual interactions.

In Florence, Italy, the organization of these events is carried out by the cultural association "Caffè-Scienza" (of which two of the authors are members), formed mostly by academic and CNR researchers, but also many "ordinary" people. Starting from 2004, this association is organizing the traditional science cafés (caffè-scienza) and other initiatives, almost one event per week. The public is mainly composed of middle-age, highly educated people.

Up to now, the Caffè-Scienza association has organized more than 300 events, with several variations: in markets, in libraries, streamed on YouTube, with online participation of experts, using movies (Cine-Scienza), and so on (Figure 1). The association also experimented with radio support (nine years) and animated the Italian Network of Science Cafés. The themes are varied, covering science and technological topics. Science cafés have also been used as an instrument for evaluating and discussing the results of European projects, as well as to co-design new ones.

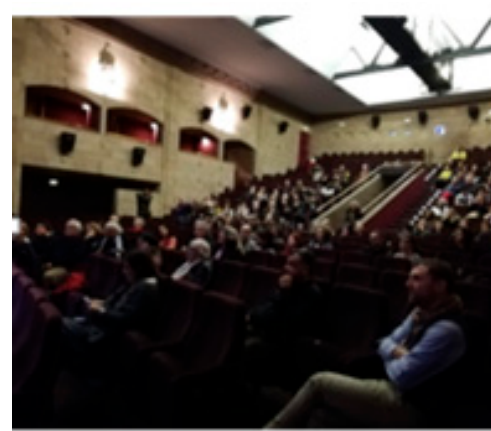

(a)

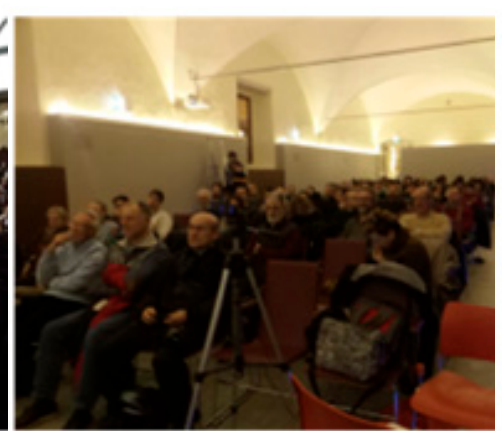

(b)

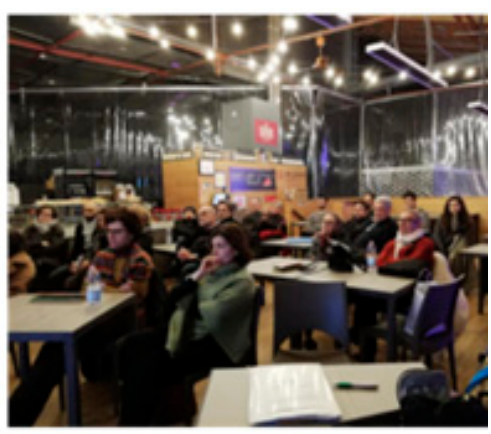

(c)

Figure 1. Different modalities of Science cafés: (a) in a conference room of the public Library "Oblate", in the center of Florence; (b) a Cine-science at the Cinema "La Compagnia", Florence; and (c) a science café in the Central Market of Florence.

In Rome, the science café activity is carried out by the non-profit association "FormaScienza" (of which one of the authors is a member), formed by academic researchers, teachers, and artists, but also "ordinary" people. This association organizes, from 2005, the science cafés and other initiatives such as the junior science cafés (with high school students), science education research, teachers and student trainings, science labs, science theatre events, and science festival. In this case as well, the public is mainly composed of middle-age, highly educated people, with a strong component of high-school students, motivated by their teachers.

\section{Science Shops}

A science shop ("shop" in the sense of "exhibition"; they are more similar to "windows" or "counters") is a methodology by which universities and research centers can offer services to the population.

Citizens can express requests and needs, and, if these themes can give origin to research, they are assigned to university students as part of their $\mathrm{PhD}$, master, or bachelor degree; part of their traineeship; or part of an examination, always under the guidance of a researcher. The results are then presented to the population. 
Science shops [21] are one of the practical realizations of the principle that the universities and research institutes should open their doors offering services directly addressed to citizens, clearly combining them with their fundamental mission of education, formation, and research.

In fact, in addition to the classic missions of the universities, such as teaching and research, a third mission was added in the last years in Italy, concerning the transfer of research results to society. It regards both the technological transfer of research (patents, spin-offs, third-party contracts and agreements, and intermediaries) and the production of social and cultural public goods (public engagement, cultural heritage, continuous training, popularization, and mass education).

In a certain sense, since in Italy universities are funded at least in part by resources coming from the general taxation, this engagement provides a return on the investments to the civil society and the socioeconomic structures of the society.

The activities belonging to the third mission contribute, in Italy and other countries, to the evaluation of the universities and research centers and thus concur to the establishment of their level of public funding.

At present, some of the authors are participating in the European project about science shops, InSPIRES (Ingenious Science shops to promote Participatory Innovation, Research and Equity in Science), contributing with their experiences about science cafés [22].

One of the main goals of this project is experimenting with a more participative approach, in which the research proposal is discussed in a public event and citizens are directly involved in the investigation, in a way similar to citizen science.

The Florence Science Shop is trying to involve throughout the process not only the associations and the stakeholders involved in the research question, but the whole citizenship, opening the doors to citizens in the beginning phase, in the development phase, and in the final dissemination phase. This goal is pursued by a strict collaboration with the Caffè-Scienza association, using the science cafés as the main channel for engagement and evaluation of the projects. Another goal is that of using the Internet in a more effective way for the science shop purposes [23].

\section{Communication during the Lockdown and the Genesis of Online Science Cafés}

Italy was one of the first countries that suffered from COVID-19 in the world. Initially, many of the politicians and scientists did not realize what was going on and the news in the newspapers was fragmented and conflicting about the danger, the measures to be taken, and the social distances to be adopted.

Not only in Italy but almost everywhere in the world the misinformation has a big role [24] so that it was necessary to coin the word infodemic: the dissemination of a huge amount of information, coming from different sources and on an often-unverifiable basis.

Infodemic, composed of info(rmation) and (epi)demic, is a word created by David J. Rothkopf in 2003 in an article published in the Washington Post entitled "When the Buzz Bites Back" [25] about a virus that travels "at the speed of light" and feeds in the most disparate ways; a scenario that today-unfortunately-we see grow in front of our eyes.

"A few facts, mixed with fear, speculation and rumor, amplified and relayed swiftly worldwide by modern information technologies, have affected national and international economies, politics and even security in ways that are utterly disproportionate with the root realities" [25].

The fight against COVID-19 pandemics has therefore faced difficulties, related to both bio/technological and cultural aspects: the problem of curing the infection and stopping the spread of the virus and the difficulty of countering the proliferation of fake and approximate news or false pieces of information.

Another example is the proliferation of "fake images", as reported by Andreu-Sánchez, Martín-Pascual and Fake [26]. This aspect is so severe that, in the communication to the public, the media also used multiple inaccurate images of the coronavirus, often taking from photo archives or 
those freely available. The article shows that the use of fake, unrealistic, or aesthetically retouched illustrations is more common than real or scientific photographs of the virus.

Citizens have been literally overwhelmed by a huge amount of contradictory information that increased their discomfort and fear. For this, at the beginning of the diffusion of Coronavirus, most of the audience of the "traditional" Science Café asked the associations described in Section 3 to help them to discuss with scientists about topics on COVID-19.

On the other hand, the experts started to discuss among them on the analysis of the first data on the infections and mortality, the necessary containment measures, and the possible treatments. They started to feel the need to open the discussion to the public, and therefore they also asked our associations to organize Science Cafés. At the same time, the science cafe associations were obliged to cancel all the scheduled face-to-face events.

In the previous years, both the Florence and Rome associations used to stream their face-to-face Science Cafés either on YouTube or through a platform developed in a previous European project (SciCafé 2.0) but all events were organized having in mind the public in presence.

Our core idea was that of exploiting the science cafés themselves not only as an engagement tool, but as the output of the science shop projects, arisen after a need expressed by citizens. In particular, we received many requests of using this type of communication methodology to discuss "hot topics" (such as aspects related to the Coronavirus disease) and in general other scientific and technological themes, overcoming the lockdown measure though the Internet.

The two associations independently decided to experiment with fully online events with public, facilitators, and experts at distance, thanks to the free apps StreamYard for Florence and Zoom for Rome, streaming the videos on YouTube and Facebook and to use YouTube/Facebook chats as our "discussion corner" with the public.

Tables 1 and 2 list the online Science Cafés and the number of visualizations as of 12th May 2020.

Table 1. List of online Science Cafés organized by "Associazione Caffè-Scienza", Firenze.

\begin{tabular}{|c|c|c|c|}
\hline Date & Title & URL & Visualizations \\
\hline $19 / 03 / 20$ & $\begin{array}{l}\text { Isolations, quarantines and } \\
\text { space missions }\end{array}$ & $\begin{array}{c}\text { https://www.youtube.com/watch?v=B- } \\
\text { 1X5JIA0GY }\end{array}$ & 430 \\
\hline $26 / 03 / 20$ & Living restricted & $\begin{array}{c}\text { https://www.youtube.com/watch?v= } \\
\text { uLm_L8m4r3A }\end{array}$ & 514 \\
\hline $02 / 04 / 20$ & Viral plots & $\begin{array}{c}\text { https://www.youtube.com/watch?v= } \\
\text { biKNpgmcCLw }\end{array}$ & 1038 \\
\hline $07 / 04 / 20$ & Extraterrestrial lands & $\begin{array}{c}\text { https://www.youtube.com/watch?v= } \\
\text { sUEt8uAZvGk }\end{array}$ & 518 \\
\hline $09 / 04 / 20$ & Time in physics & $\begin{array}{c}\text { https://www.youtube.com/watch?v= } \\
\text { WSG2wck5Go4 }\end{array}$ & 614 \\
\hline $16 / 04 / 20$ & $\begin{array}{l}\text { From the nebulae to the } \\
\text { origin of life on Earth }\end{array}$ & $\begin{array}{c}\text { https://www.youtube.com/watch?v= } \\
\text { krkYqDrTaZA }\end{array}$ & 533 \\
\hline $23 / 04 / 20$ & $\begin{array}{l}\text { Vaccines, between facts and } \\
\text { lies }\end{array}$ & $\begin{array}{c}\text { https://www.youtube.com/watch?v= } \\
\text { fWpup6YNNUE }\end{array}$ & 545 \\
\hline $30 / 04 / 20$ & $\begin{array}{l}\text { History of Mars exploration: } \\
\text { past, present, future }\end{array}$ & $\begin{array}{c}\text { https://www.youtube.com/watch?v= } \\
\text { wryKckXtwak }\end{array}$ & 513 \\
\hline $07 / 05 / 20$ & $\begin{array}{l}\text { SARS COV-2 between } \\
\text { immune response and } \\
\text { spillover }\end{array}$ & $\begin{array}{c}\text { https://www.youtube.com/watch?v= } \\
\text { N3d2yFBVxsw }\end{array}$ & 918 \\
\hline
\end{tabular}


Table 2. List of online Science Cafés organized by "FormaScienza", Roma.

\begin{tabular}{|c|c|c|c|}
\hline Date & Title & URL & Visualizations \\
\hline $30 / 03 / 20$ & $\begin{array}{l}\text { Covid-19: data \& } \\
\text { challenges }\end{array}$ & $\begin{array}{l}\text { https://www.youtube.com/watch? } \\
\text { v=4bs7F5YEBIo }\end{array}$ & 11.713 \\
\hline $30 / 04 / 20$ & $\begin{array}{l}\text { Covid-19: health \& } \\
\text { psychosocial scenarios }\end{array}$ & $\begin{array}{l}\text { https://www.youtube.com/watch? } \\
\text { v=24QyRCDN4L4 }\end{array}$ & 7.897 \\
\hline $13 / 05 / 20$ & $\begin{array}{l}\text { Covid-19 \& mental } \\
\text { health }\end{array}$ & $\begin{array}{l}\text { https://www.youtube.com/watch? } \\
\text { v=y_FdleduIY0 }\end{array}$ & to do \\
\hline
\end{tabular}

As shown in Tables 1 and 2, in Florence, we decided to schedule an event per week and to discuss not only topics related to COVID-19 but also scientific and technological ones. In Rome, the schedule of the science café was impromptu, based on the requests of experts and public.

In all the events organized, we noticed a good appreciation of the public, both for the numbers of people who followed us and for the chat discussion, which are visible on YouTube and Facebook.

There were large synchronous public groups (Florence 100, Rome 1000) that actively participated in the discussion with many questions and comments in the chat, which in some cases became a "parallel world" where to discuss.

The most successful science café was the one organized in Rome on "Covid-19: data \& challenge". The experts, Federico Ricci Tersenghi, Ernesto Burgio, and Andrea Crisanti, were fundamental for the success of this event because they had already begun to publish data analysis and to disclose them on Facebook and other social networks, with a large "following of followers". Actually, they pushed strongly for having a direct contact with the public.

It is very interesting to see, thanks to YouTube analytics, that, immediately after the live streaming, 3000 other people followed the video, and that views continue to increase every day, with a peak in correspondence with the report of the Science Café published on ww.post.it (17 April 2020) (see Figure 2).

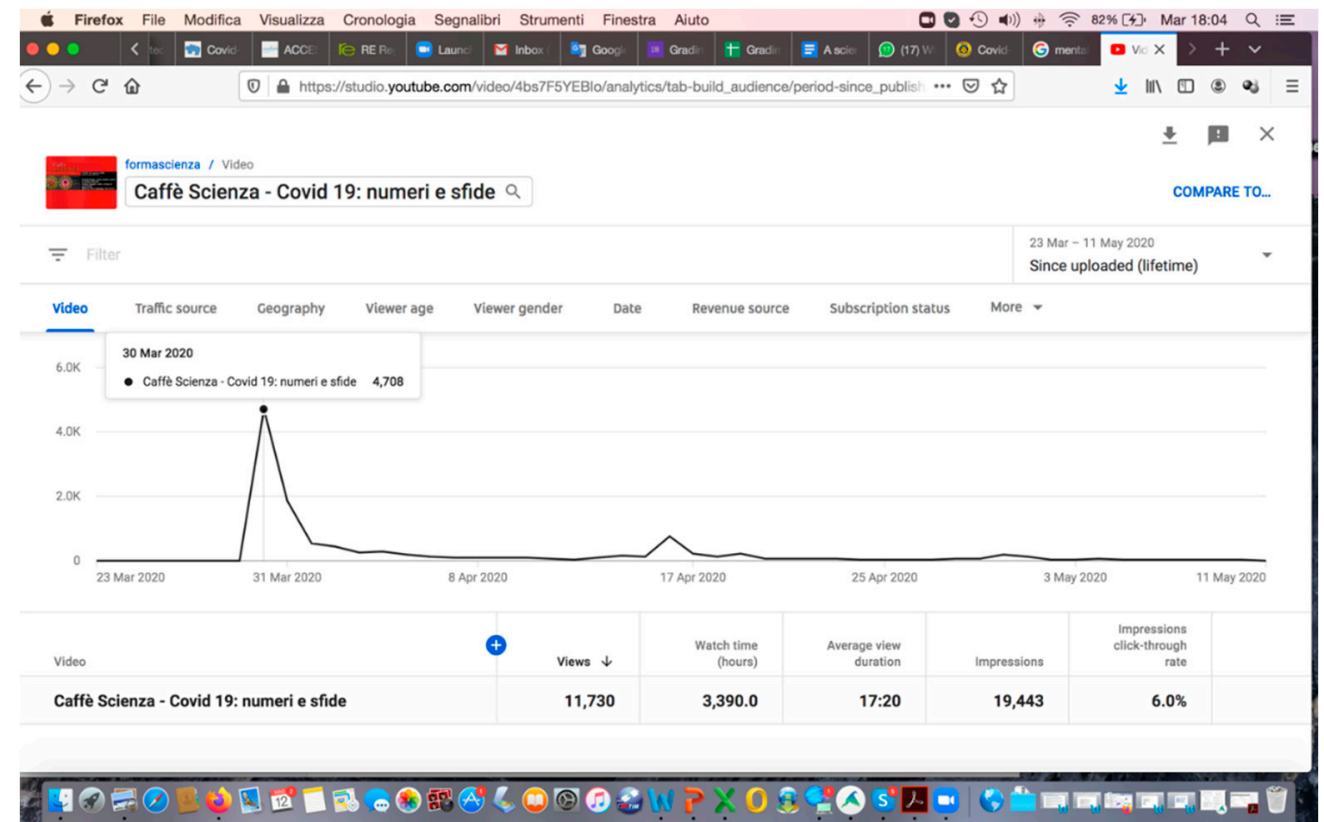

Figure 2. YouTube analytics for the number of views for the first Rome online science café. The $4.5 \mathrm{k}$ peak on 31st March includes the more that 1000 synchronous views and the about $3.0 \mathrm{k}$ views immediately after the conclusion.

The geographical location is also interesting because the public not only participated from Italy: probably, most of the public is informed by word of mouth, spreading all over the world (Figure 3). 


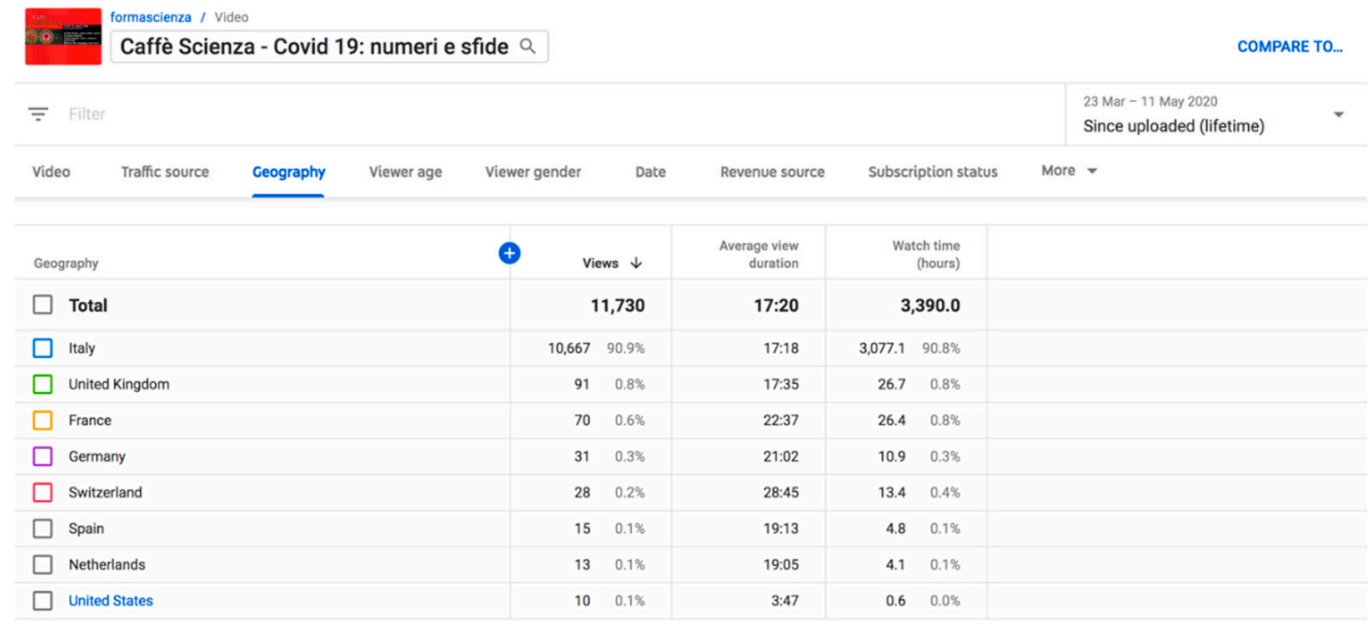

Figure 3. YouTube analytics showing geographic locations for the first Rome online science café.

An interesting observation about the interactions is that, in the traditional live science café, the main role of the moderator is that of promoting questions but also containing the exuberance of the public, which sometimes takes minutes to formulate a question or a comment. In live science cafés, this exuberance may impede further questions, due to time limits. In the online version, one is free to ask and comment on the textual chat, which essentially constitutes a parallel discussion channel. In this case, the number of comments does not affect the possibility of commenting, and the role of moderator is that of reporting questions to experts, keeping track of the interventions, resuming the longer ones, and resuming those that are just repetitions.

As for live science cafés, the online version differs from other online communication methods (YouTube videos, Facebook posts, etc.) because one of its main components is the large amount of time dedicated to questions from participants to experts.

Another important point shared by live and online science cafés is the "education" aspects towards experts, who are confronted with the "real" public and have to learn how to defend their positions and which are the typical fears and doubts to be addressed. Moreover, new ideas and new communication approaches can arise from this interaction.

\section{The Online Science Café as a Tool for High Schools}

The project was born thanks to the collaboration between us and the secondary high school "Liceo Giotto Ulivi" of a little town near Florence, Borgo san Lorenzo, that developed for years a campaign on blood and stem cell donation.

This project had the main purpose of developing specific scientific skills on stem cells and their therapeutic use. The organizers wanted to inform and educate high school students on the theme of donation as well as thinking on social solidarity. The topics covered were the donation of blood and stem cells. The project included a part of teaching with conferences and a part of laboratory.

The teachers had to redesign the project due to the limitations during the lockdown and, knowing the Florence Science Café association, asked for help. The response was developed with two online events:

- One online Science Café with many experts (Figure 4):

Dr. Stefano Guidi, head of the Bone Marrow Transplant Center of the Careggi Hospital (Florence).

○ Sabina Mazzoldi, president of the Sofia Luce Rebuffat Onlus Foundation and teacher of the Giotto Ulivi High School.

Anna Pieri, former student of Giotto Ulivi High School, student of Medicine and enrolled in the register of stem cell donors (IBMDR). 
Cristina Carla, teacher of the Giotto Ulivi High School.

- A final meeting of the project designed as an online Science Café with:

Dr. Franco Vocioni, head of the transfusion center of the Mugello Hospital.

Prof. Daniele Bani, Department of experimental and clinical medicine of the University of Florence.

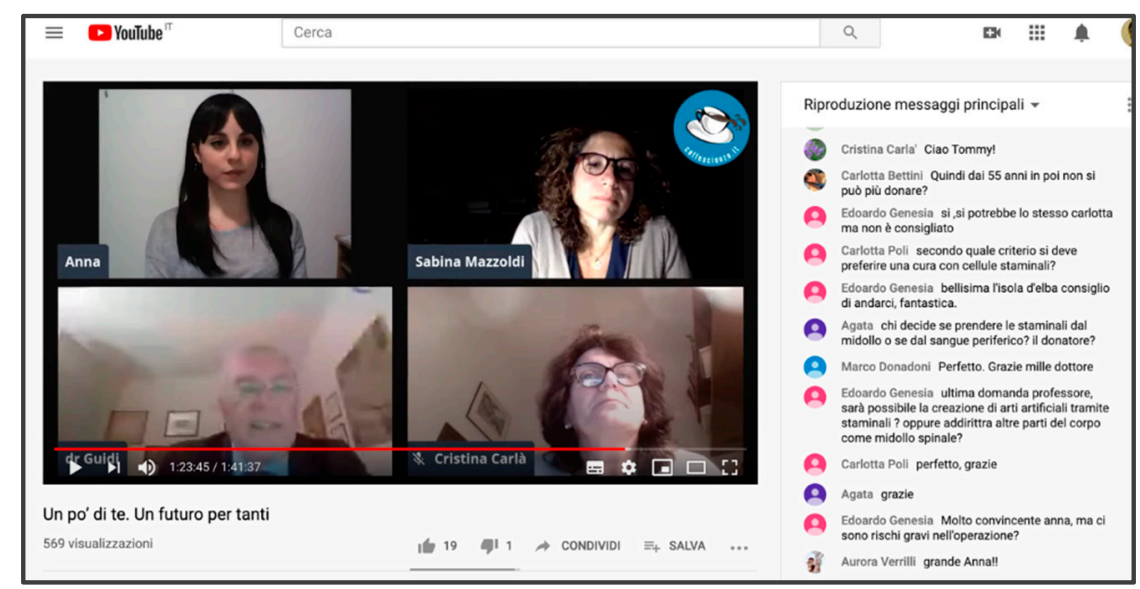

Figure 4. A moment of the Science Café demanded by the high school.

Both events went well, with a large participation of students (more than 100 participants) who animated, with their questions and comments, the chat and the discussion (see, for instance, [27] with about 50 comments). The teachers were satisfied with the success in terms of numbers and participation.

\section{A Survey to Understand the Approval of Public}

We wondered if this new way to implement Science Cafés, once the emergency is over, will remain among those used by our associations or if, once the lockdown is over, we shall have to return to traditional science cafes. Thus, we decided to develop an online questionnaire to understand the feelings of the public regarding the new modality.

The questionnaire has the purpose of determining the level of appreciation of the activities and understanding which method the public prefers between the one in attendance, the one with the stream of an event in attendance, or an entirely online event. Up to now, 120 people have answered.

Some preliminary results are:

- $\quad$ The audience is of medium-high age (78\% are over 40$)$.

- $\quad$ They are mainly located in the North and Center Italy.

- A large part of the public has also followed events in attendance in past years, but 30\% are "new" audience members.

- Most of the audience (70\%) use a PC, the remaining tablets or smartphones.

- $\quad$ The audience appreciates both the online and face-to-face modalities, as can be seen in Figure 5. 


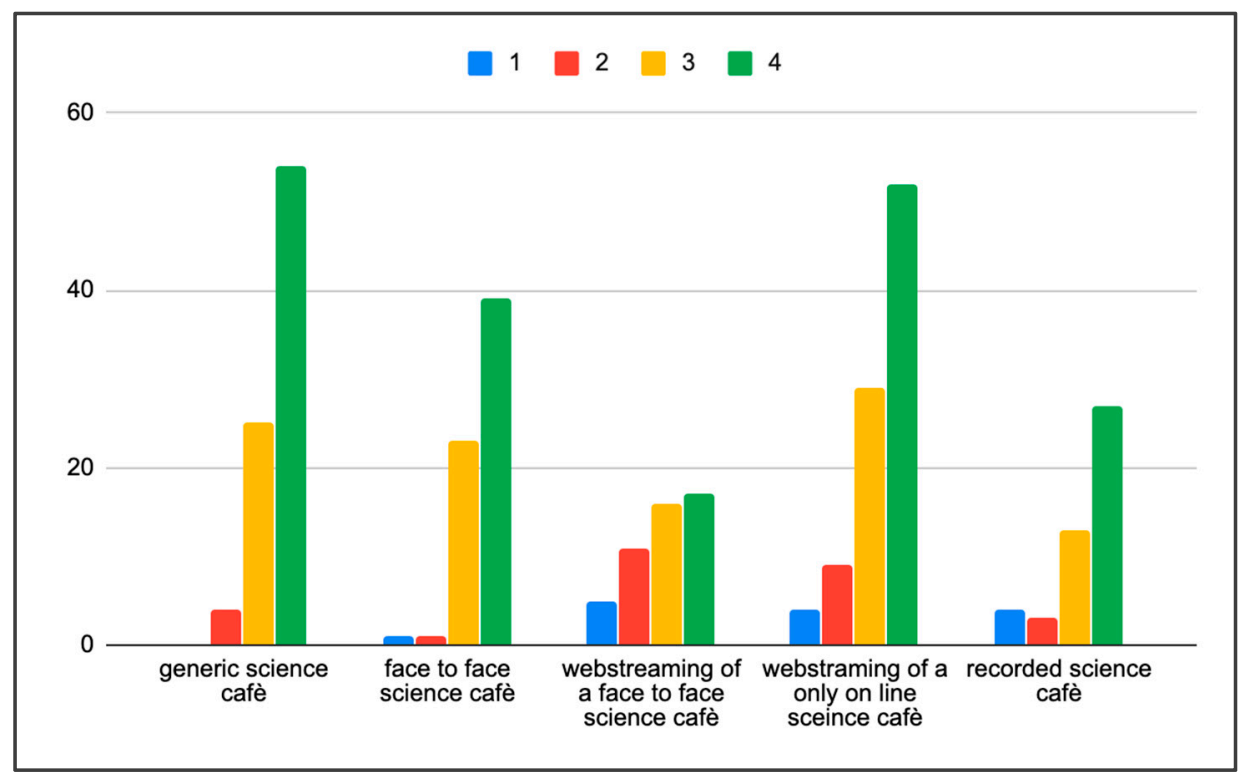

Figure 5. Approval of the various modalities of science Café from 1 (not good) to 4 (optimum).

By analyzing the data, we can say that about $1 / 4$ of the audience of online science cafés has never attended a live version.

As shown in Table 3, there is a slight preference of younger people towards online events, while for older people there is no specific difference.

Table 3. Average approval of the various modalities per age class. Votes range from 1 (not good) to 4 (optimum).

\begin{tabular}{cccc}
\hline Age & Science Café in General & Face to Face Event & Online Event \\
\hline $25-30$ & 3.80 & 3.85 & 4.00 \\
$31-40$ & 3.72 & 3.28 & 3.33 \\
$41-60$ & 3.61 & $3, .73$ & 3.73 \\
$>60$ & 3.61 & 3.59 & 3.57 \\
\hline
\end{tabular}

\section{Conclusions}

We think that the lockdown experience, which has been indeed traumatic and quite impacting on the economic and social aspects, offered nevertheless the possibility of experiencing some novelties that could be maintained. First, from the environmental point of view, lower levels of pollutions have been recorded worldwide. We have also appreciated the possibility of lowering the level of consumption (and of wastes). There has also been an increasing familiarity with online tools, which may be exploited in the future to reduce commuting and increase smart working.

Among the several initiatives, our sister associations responded to the communication and information needs of citizens and experts by quickly organizing a fully online version of our traditional science cafés, with good results and appreciation from our public. We expect that this modality will persist in the future, possibly alongside the classical face-to-face modality.

In conclusion, we can say that the online version of the science café enlarged the traditional audience, both numerically and geographically, and also facilitated the discussion since the number of interventions by chat is larger than the typical oral interventions. We are not able to assess the role of science cafés in educating the people (and the expert) towards a more "scientific" and rational approach to the subject of discussion, but it is evident from the fidelity of the public that this methodology has a positive effect on their life. 
The present article is an extended version of one presented at the conference INSCI 2019 [23]; with respect to that version, we added the report on the Rome experience and the part on online science cafés.

Author Contributions: Conceptualization, G.P. and F.B.; funding acquisition, F.B.; investigation, G.P., C.B. and F.B.; methodology, F.B.; project administration, F.B.; writing—original draft, G.P. and F.B. All authors have read and agreed to the published version of the manuscript.

Funding: This project has received funding from the European Union's Horizon 2020 research and innovation program under grant agreement No. 74167 (InSPIRES project).

Acknowledgments: The Florence Science Shop "La bottega della Scienza e della Sostenibilità a Firenze" was born thanks to the EU project InSPIRES, "Ingenious Science shops to promote Participatory Innovation, Research and Equity in Science".

Conflicts of Interest: The authors declare no conflict of interest.

\section{References}

1. Capasso, V.; Serio, G. A Generalization of the Karmak-McKendrick Deterministic Epidemic Model. Math. Biosci. 1978, 42, 43-61. [CrossRef]

2. Bagnoli, F.; Lió, P.; Sguanci, L. Risk perception in epidemic modeling. Phys. Rev. E 2007, 76, 061904. [CrossRef] [PubMed]

3. D'Onofro, A.; Manfredi, P. Information-related changes in contact patterns may trigger oscillations in the endemic prevalence of infectious diseases. J. Theor. Biol. 2009, 256, 473-478. [CrossRef] [PubMed]

4. Manfredi, P.; d'Onofro, A. (Eds.) Modeling the Interplay between Human Behavior and the Spread of Infectious Diseases; Springer: New York, NY, USA, 2013.

5. Bagnoli, F.; Lorini, D.; Lió, P. Modeling social groups, policies and cognitive behavior in COVID-19 epidemic phases. Basic scenarios. Substantia 2020, 4 (Suppl. 1), 914.

6. Sestini, F. Collective awareness platforms: Engines for sustainability and ethics. IEEE Technol. Soc. Mag. 2012, 12, 53. [CrossRef]

7. Arniani, M.; Badii, A.; De Liddo, A.; Georgi, A.; Passani, A.; Piccolo, L.; Teli, M. Collective Awareness Platforms for Sustainability and Social Innovation: An Introduction. 2014. Available online: http://www.transitsocialinnovation.eu/resource-hub/collective-awareness-platforms-forsustainability-and-social-innovation--an-introduction (accessed on 1 July 2020).

8. Badii, A.; Bagnoli, F.; Balazs, B.; Castellani, T.; D’Orazio, D.; Ferri, F.; Grifoni, P.; Pacini, G.; Serban, O.; Valente, A. Collective awareness platforms and digital social innovation mediating consensus seeking in problem situations. In Proceedings of the Conference INSCI 2016. LNCS; Springer: Cham, Switzerland, 2016; Volume 9934, pp. 55-65.

9. Pacini, G.; Bagnoli, F. Results of a collective awareness platforms investigation. In Internet Science, Proceedings of the Conference INSCI 2016. LNCS; Springer: Cham, Switzerland, 2016; Volume 9934, p. 9934.

10. Bagnoli, F.; Guazzini, A.; Pacini, G.; Stavrakakis, I.; Kokolaki, E.; Theodorakopoulos, G. Cognitive structure of collective awareness platform. In Proceedings of the IEEE Eighth International Conference on Self-adaptive and Self-organizing Systems Workshops (SASOW), London, UK, 8-12 September 2014; pp. 96-101.

11. CSDC. Available online: www.csdc.unifi.it (accessed on 1 July 2020).

12. University of Florence. Available online: www.unifi.it (accessed on 1 July 2020).

13. University of Florence. Sportello della Scienza e della Sostenibiulità. Available online: https://www. ateneosostenibile.unifi.it/vp-161-sportello-della-scienza-e-della-sostenibilita.html (accessed on 1 July 2020).

14. InSPIRES Project. Web Site. Available online: www.inspiresproject.eu (accessed on 1 July 2020).

15. Owen, R.; Macnaghten, P.; Stilgoe, J. Responsible research and innovation: From science in society to science for society, with society. Sci. Public Policy 2012, 39, 751-760. [CrossRef]

16. Dallas, D. The café scientifique. Nature 1999, 399, 120. [CrossRef]

17. Ferris, D. Science Cafés Tap Nation's Fascination with Research and Discoveries. 2007. Available online: https: //www.wired.com/2007/12/science-cafs-tap-nations-fascination-with-research-and-discoveries/ (accessed on 1 July 2020).

18. Bagnoli, F.; Pacini, G.; Politi, P. Science is ready, serve it! Europhys. News 2011, 42.

19. Bagnoli, F.; Pacini, G. Sipping Science in a Café. Procedia Comput. Sci. 2011, 7, 194-196. [CrossRef] 
20. Pacini, G.; Bagnoli, F. Science Cafés in the Internet Era. In Proceedings of the Conference INSCI 2017, LNCS 10673; Springer International Publishing AG: Cham, Switzerland, 2017; pp. 79-89.

21. European Commission. EUR 20877 "Science Shops-Knowledge for the Community"; Office for Official Publications of the European Communities: Luxembourg, 2003.

22. Pacini, G.; Bagnoli, F. InSPIRES: Science Shops 2.0. In Proceedings of the Conference INSCI 2017, LNCS 10673; Kompatsiaris, I., Ed.; Springer International Publishing AG: Cham, Switzerland, 2017; pp. 69-78.

23. Pacini, G.; Bagnoli, F. Science Cafés and Science Shops for Public Engagement. In Internet Science, Proceedings of the Conference INSCI 2019, LNCS 11938; El Yacoubi, S., Bagnoli, F., Pacini, G., Eds.; Springer Nature Switzerland AG: Cham, Switzerland, 2019; pp. 97-108.

24. Mian, A.; Khan, S. Coronavirus: The Spread of Misinformation. BMC Med. 2020, 18, 1-2. [CrossRef] [PubMed]

25. Rothkopf, D.J. When the Buzz Bites Back. 2003. Available online: http://www1.udel.edu/globalagenda/2004/ student/readings/infodemic.html (accessed on 1 July 2020).

26. Andreu-Sánchez, C.; Martín-Pascual, M.-A. Fake images of the SARS-CoV-2 coronavirus in the communication of information at the beginning of the first Covid-19 pandemic. Prof. Inf. 2020, 29. [CrossRef]

27. Caffè-Scienza Firenze. Un po' di te. Un Futuro per Tanti. 2020. Available online: https://youtu.be/ B6Oxd2POOxE (accessed on 1 July 2020).

(C) 2020 by the authors. Licensee MDPI, Basel, Switzerland. This article is an open access article distributed under the terms and conditions of the Creative Commons Attribution (CC BY) license (http://creativecommons.org/licenses/by/4.0/). 